\title{
Hidrokarbon Hasil Perengkahan Sampah Polystyrene Foam
}

\author{
Ella Melyna ${ }^{1 *}$ \\ ${ }^{1}$ Program Studi Teknik Kimia Polimer, Politeknik STMI Jakarta \\ Jl. Letjend Suprapto No. 26 Jakarta Pusat \\ * Corresponding author: ellamelyna@stmi.ac.id
}

\begin{abstract}
ABSTRAK
Polystyrene foam atau yang lebih dikenal styrofoam banyak digunakan untuk kemasan, bahan kerajinan, dekorasi, bahan bangunan, dan sebagainya. Namun penggunaan polystyrene foam untuk kemasan masih menimbulkan beberapa kontroversi. Beberapa pandangan negatif muncul mengenai penggunaan polystyrene foam seperti menyebabkan masalah kesehatan dan lingkungan. Menurut aspek lingkungan, polystyrene foam merupakan material yang sulit terurai secara alami oleh alam. Penanganan sampah polystyrene foam yang sebatas pembuangan saja akan membebani alam dalam penguraiannya. Oleh karena itu kegiatan pengelolaan sampah polystyrene foam perlu dilakukan. Salah satu metode pengelolaan sampah polystyrene foam untuk dijadikan suatu produk yang lebih berguna dan bermanfaat bagi masyarakat pada masa yang akan datang adalah mengkonversi sampah polystyrene foam menjadi bahan bakar. Bagaimanapun juga dilihat dari bahan dasarnya sampah polystyrene foam berpotensi mempunyai nilai ekonomis sebagai sumber bahan baku jika diolah dengan cara yang tepat yaitu akan menghasilkan hidrokarbon sebagai bahan dasar energi. Konversi sampah polystyrene foam menjadi bahan bakar adalah dengan cara perengkahan sampah polystyrene foam menggunakan katalis (catalytic cracking) yang dijalankan pada suhu lebih rendah daripada thermal cracking. Pada penelitian ini, sampah polystyrene foam direngkah menggunakan katalis $\mathrm{H}$-Zeolit pada suhu $360^{\circ} \mathrm{C}$. Hasil perengkahan sampah polystyrene foam dianalisa menggunakan alat GC-MS. Hasil perengkahan sampah polystyrene foam pada suhu $360^{\circ} \mathrm{C}$ dengan katalis $\mathrm{H}$-Zeolit menghasilkan $85,52 \%$ fraksi gasoline dan 7,4\% fraksi kerosin dan diesel dengan komposisi fraksi gasoline 100\% golongan aromatik. Kandungan senyawa aromatik yang tinggi dalam gasoline bersifat karsinogen, sebagai pembentuk deposit dan penyumbang emisi gas buang berbahaya.
\end{abstract}

Kata Kunci: Aromatik, Gasoline, Polystyrene Foam

\section{PENDAHULUAN}

Polystyrene foam atau yang lebih dikenal styrofoam adalah salah satu jenis polimer yang terdiri dari monomer stirena. Polystyrene foam termasuk dalam plastik kode 6. Polystyrene foam bersifat lunak, ringan, murah dan praktis. Pada umumnya, polystyrene foam dapat digunakan untuk kemasan, bahan kerajinan, dekorasi, bahan bangunan, dan sebagainya. Namun penggunaan polystyrene foam untuk kemasan masih menimbulkan beberapa kontroversi. Beberapa pandangan negatif muncul mengenai penggunaan polystyrene foam seperti menyebabkan masalah kesehatan dan lingkungan.

Menurut aspek lingkungan, ada beberapa kota besar di dunia yang pernah mengeluarkan peraturan untuk melarang polystyrene foam sebagai kemasan makanan atau minuman, seperti Oxford, London, San Fransisko, dan New
York. Di Indonesia, pemanfaatan polystyrene foam untuk kemasan makanan oleh pedagang kaki lima atau restoran telah dilarang di Bandung sejak 1 November 2016. Hal ini disebabkan oleh penumpukan sampah polystyrene foam yang dapat menghambat arus sungai dan menyebabkan banjir.

Studi monitoring bulanan sampah yang hasilnya dipublikasikan pada Tanggal 10 Desember 2019 mengidentifikasi enam tipe sampah dan 19 kategori sampah plastik dari sembilan muara sungai di Jakarta, Tangerang, dan Bekasi selama Juni 2015 sampai 2016 [1]. Berdasarkan hasil riset, peneliti mengestimasi aliran sampah dari kawasan Jakarta, Tangerang, dan Bekasi sampai 8,32 ton per hari, delapan sampai 16 kali lebih rendah dibandingkan dengan estimasi dalam studi-studi berbasis model [1]. 
Berdasarkan persentase 19 kategori sampah plastik yang dikumpulkan di sembilan hilir sungai di Kota Tangerang, Jakarta, dan Bekasi yang berakhir di Teluk Jakarta, sumbangan polystyrene Tangerang 31,69 persen, Jakarta 11,47 persen, dan Bekasi 25,45 persen [1]. Polystyrene foam merupakan material yang sulit terurai secara alami oleh alam. Penanganan sampah polystyrene foam yang sebatas pembuangan saja akan membebani alam dalam penguraiannya. Oleh karena itu kegiatan pengelolaan sampah polystyrene foam perlu dilakukan.

Salah satu metode pengelolaan sampah polystyrene foam untuk dijadikan suatu produk yang lebih berguna dan bermanfaat bagi masyarakat pada masa yang akan datang adalah mengkonversi sampah polystyrene foam menjadi bahan bakar. Bagaimanapun juga dilihat dari bahan dasarnya sampah polystyrene foam berpotensi mempunyai nilai ekonomis sebagai sumber bahan baku jika diolah dengan cara yang tepat yaitu akan menghasilkan hidrokarbon sebagai bahan dasar energi. Konversi sampah polystyrene foam menjadi bahan bakar adalah dengan cara perengkahan sampah polystyrene foam menggunakan katalis (catalytic cracking) yang dijalankan pada suhu lebih rendah daripada thermal cracking.

Lee, dkk. [2] meneliti tentang degradasi polietilen (HDPE) dan polystyrene (PS) dengan bantuan katalis FCC (Fluid Catalytic Cracking) dan beroperasi pada suhu $400^{\circ} \mathrm{C}$. Dari percobaan diperoleh bahwa gasoline yang terbentuk dari HDPE sebesar $86 \%$ dan sebesar $98 \%$ yang berasal dari PS.

Pada penelitian ini, sampah polystyrene foam akan direngkah menggunakan katalis $\mathrm{H}$-Zeolit pada suhu $360^{\circ} \mathrm{C}$. Hasil perengkahan sampah polystyrene foam dianalisa menggunakan alat GC-MS. Senyawa yang teridentifikasi dari hasil uji menggunakan GC-MS dikelompokkan ke dalam golongan hidrokarbon yang kemudian dari komposisi hidrokarbon dikategorikan ke dalam jenis bahan bakar.

Tabel 1. Komposisi golongan hidrokarbon dalam bahan bakar bensin

\begin{tabular}{lc}
\hline \multicolumn{1}{c}{ Golongan } & Komposisi \\
\hline Parafin & $49,3 \%$ \\
Olefin & $1,8 \%$ \\
Naften & $5 \%$ \\
Aromatik & $30,5 \%$ \\
\hline Sumber : Andrian [3] &
\end{tabular}

Harapannya, hidrokarbon hasil perengkahan sampah polystyrene foam menggunakan katalis $\mathrm{H}$-Zeolit masuk pada golongan hidrokarbon dalam kategori gasoline (bensin) sesuai dengan penelitian Lee, dkk. [2]. Bensin adalah bahan bakar mesin siklus Otto yang banyak digunakan sebagai bahan bakar alat transportasi darat (mobil).

Secara sederhana, bensin tersusun dari hidrokarbon rantai lurus mulai dari $\mathrm{C}_{7}$ sampai dengan $\mathrm{C}_{11}$ [4]. Kinerja yang dikehendaki dari bensin adalah anti knocking. Knocking adalah peledakan campuran (uap bensin dengan udara) di dalam silinder mesin dengan siklus Otto sebelum busi menyala. Peristiwa knocking ini sangat mengurangi daya mesin. Hidrokarbon rantai lurus cenderung membangkitkan knocking. Sementara, hidrokarbon bercabang, siklik maupun aromatik cenderung bersifat anti knocking.

Tolak ukur kualitas anti knocking sering disebut sebagai bilangan oktan (octane number) [5]. Angka oktan senyawa yang termasuk golongan aromatik dan isoalkana dapat dilihat pada Gambar 1 dan Gambar 2. 


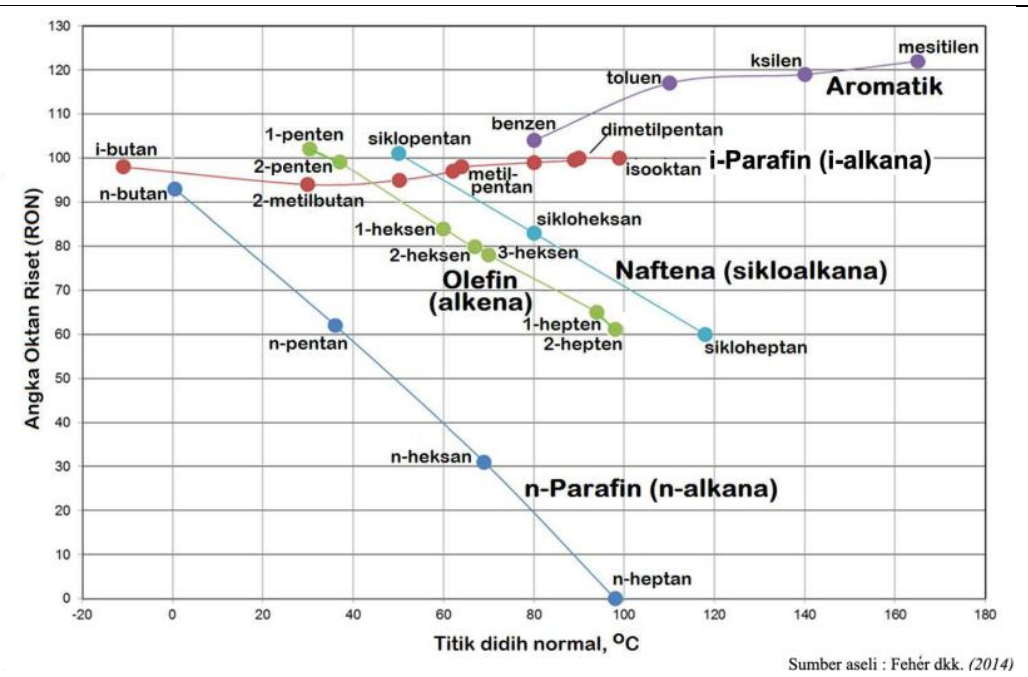

Gambar 1. Senyawa aromatik dan isoalkana memiliki angka oktan tinggi [6]

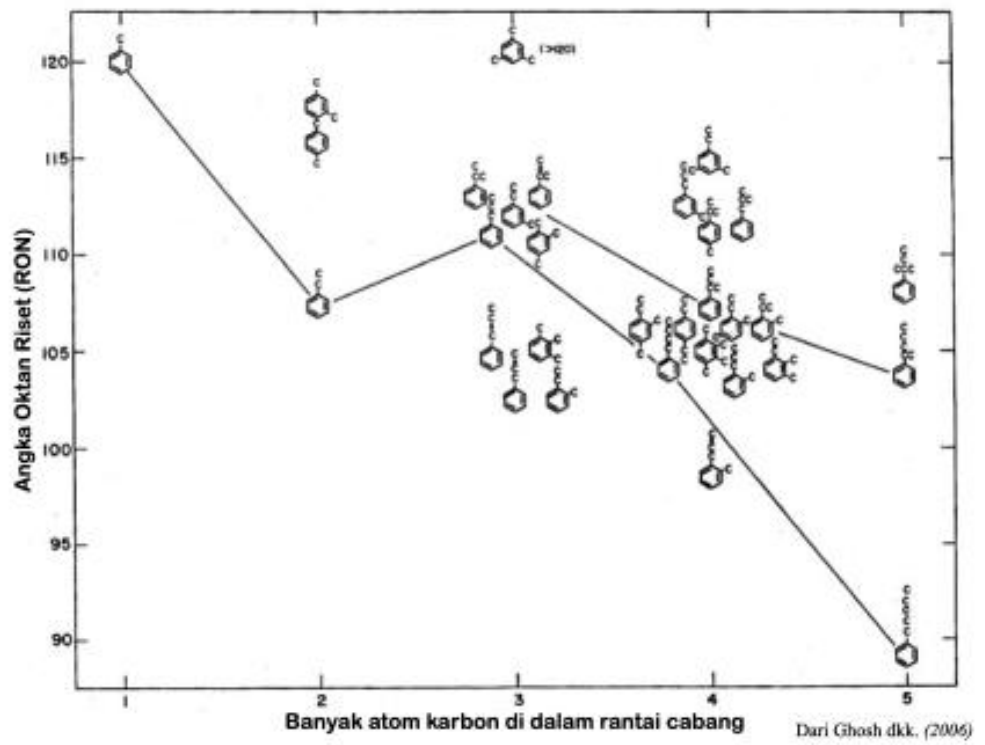

Angka oktan aromatik

Gambar 2. Angka oktan senyawa yang termasuk golongan aromatik [7]

Angka oktan (octane number) adalah tolok ukur ketahanan bahan bakar terhadap kecenderungan penyalaan mandiri tersebut. Semakin tinggi angka oktan, semakin baik ketahanannya. Angka oktan bensin diuji dengan motor/mesin standar bersilinder tunggal di laboratorium. Bergantung pada kondisi pengujian, ada 2 angka oktan : Angka Oktan Riset (atau Research Octane Number, RON) dan Angka Oktan Motor (atau Motor Octane Number, MON). RON lebih berkorelasi dengan kendaraan berkecepatan rendah dan sering ganti persneling (kondisi di pusat kota) sedang MON lebih berkorelasi dengan kondisi di jalan tol (kecepatan tinggi, jarang ganti persneling. Pengujian dilakukan dengan membandingkan unjuk kerja bahan bakar (di dalam mesin) dengan sederet bahan bakar rujukan yang berupa campuran $n$-heptana (angka oktan $=0$ ) dan isooktana (2,2,4-trimetilpentan, angka oktan $=100$ ). Nilai angka oktan sama dengan nilai persentase isooktana di dalam bahan bakar rujukan yang menghasilkan kesamaan unjuk kerja dengan bensin yang diuji [6].

\section{BAHAN DAN METODE}

\section{Bahan}

Bahan-bahan yang digunakan dalam penelitian ini adalah sampah polystyrene foam, zeolit alam, $\mathrm{NH}_{4} \mathrm{Cl} 1 \mathrm{~N}$, dan aqua demineralisasi. 


\section{Metode}

Prosedur pada penelitian ini terdiri dari persiapan bahan baku, proses perengkahan katalitik sampah polystyrene foam dan analisa produk.

\section{Persiapan bahan baku}

Polystrene foam dipotong kecil-kecil berukuran \pm $2 \times 2 \mathrm{~cm}$ untuk memperbesar luas permukaan kontak katalis dengan sampel.

\section{Perengkahan polystrene foam}

200 gram polystyrene foam yang telah dipotongpotong dicampur dengan katalis $\mathrm{H}$-Zeolit dengan rasio katalis/polystyrene foam $=30 \% \mathrm{w} / \mathrm{w}$ direngkah dalam reaktor secara batch pada suhu $360^{\circ} \mathrm{C}$.

\section{Analisa produk}

Produk dianalisa menggunakan GC-MS (Gas Cromatografi Mass Spectra) untuk mengetahui komponen yang ada dalam produk. Analisa GCMS dilakukan di Laboratorium Kimia Organik, Jurusan Kimia, FMIPA, Universitas Gajah Mada, Yogyakarta.

\section{HASIL DAN PEMBAHASAN}

Hasil analisa GC-MS menunjukkan besarnya fraksi bahan bakar berupa gasoline, kerosin dan diesel yang terkandung di dalam produk perengkahan polystyrene foam. Hasil analisa GC-MS produk dapat dilihat pada Gambar 3 dan Tabel 2.

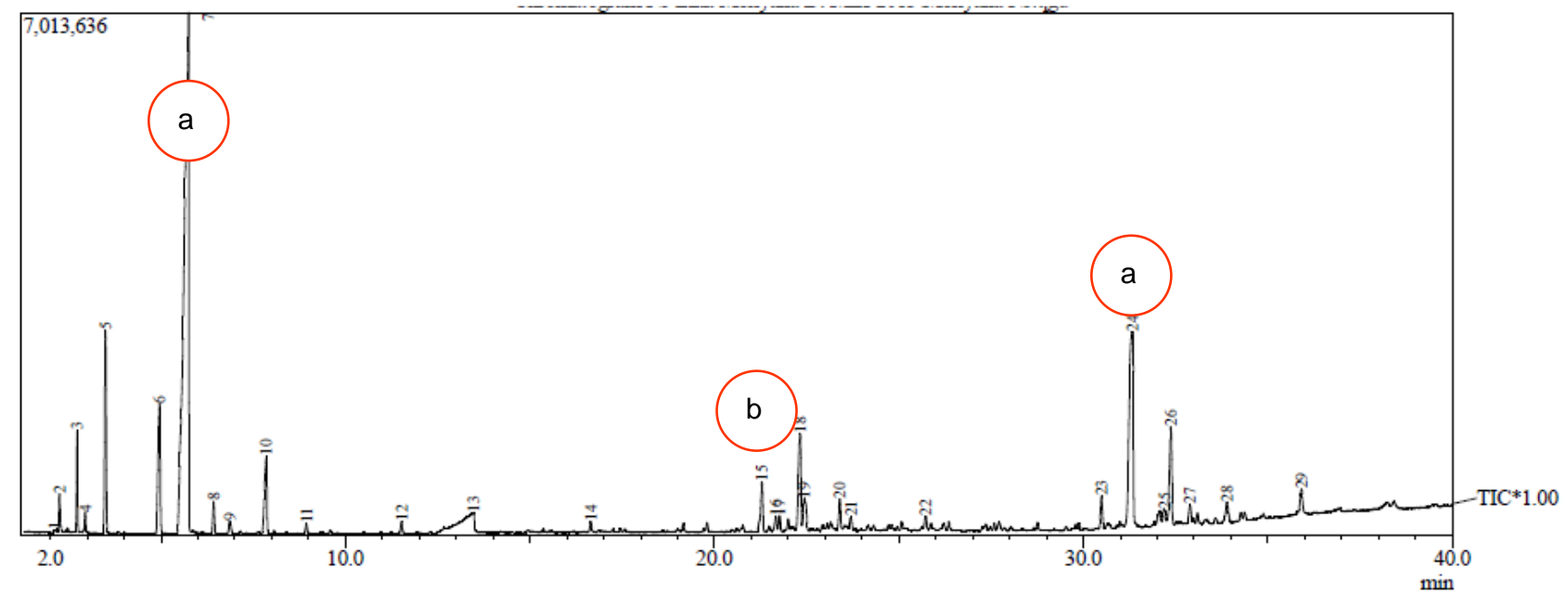

Gambar 3. Hasil GC-MS Perengkahan sampah polystyrene foam (a) fraksi gasoline dan (b) fraksi kerosin dan diesel

Tabel 2. Hasil analisa GC-MS produk

\begin{tabular}{cc}
\hline $\begin{array}{c}\text { Produk Bahan } \\
\text { Bakar }\end{array}$ & $\begin{array}{c}\text { Persen Bahan } \\
\text { Bakar }\end{array}$ \\
\hline Gasoline (\%) & 85,52 \\
Kerosin dan & 7,4 \\
Diesel (\%) & 92,92 \\
Total (\%) & 9 \\
\hline
\end{tabular}

Hidrokarbon hasil perengkahan sampah polystyrene foam berada dalam rentang panjang hidrokarbon $\mathrm{C}_{6}-\mathrm{C}_{24}$. Perengkahan polystyrene foam menghasilkan $85,52 \%$ fraksi gasoline dan $7,4 \%$ fraksi kerosin dan diesel. Dari Tabel 2 dapat dilihat bahwa fraksi bahan bakar yang paling banyak dihasilkan dari perengkahan sampah polystyrene foam yaitu fraksi gasoline.

Hal ini disebabkan karena polystyrene merupakan hidrokarbon aromatik dengan rumus molekul $\left(\mathrm{C}_{8} \mathrm{H}_{8}\right) \mathrm{n}$ dimana jumlah atom $\mathrm{C}$ polystyrene berada pada rentang panjang hidrokarbon $\mathrm{C}_{7}-\mathrm{C}_{11}$ yang termasuk ke dalam kategori bahan bakar gasoline. 
Tabel 3. Komposisi fraksi gasoline hasil perengkahan sampah polystyrene foam

\begin{tabular}{lcc}
\hline \multicolumn{1}{c}{ Golongan } & Gasoline $^{*}$ & PS \\
\hline Parafin (\%) & 49,3 & 0 \\
Olefin (\%) & 1,8 & 0 \\
Naften (\%) & 5 & 0 \\
Aromatik (\%) & 30,5 & 100 \\
\hline
\end{tabular}

*Sumber : Adrian [3]

Komposisi fraksi gasoline dari perengkahan sampah polystyrene foam menghasilkan 100\% gologan aromatik. Hal ini disebatkan karena polystyrene merupakan senyawa aromatik dan ketika direngkah pada suhu $360^{\circ} \mathrm{C}$ dengan katalis $\mathrm{H}$-Zeolit ternyata rantai senyawa aromatiknya belum putus. Hal ini juga menunjukkan bahwa katalis $\mathrm{H}$-Zeolit tidak bisa memutus rantai senyawa aromatik.

Golongan aromatik memiliki angka oktan yang tinggi dibandingkan golongan parafin, olefin, dan sikloalkana. Hasil perengkahan sampah polystyrene foam yang menghasilkan 100\% gologan aromatik membuat angka oktan produk perengkahan sampah polystyrene foam yang tinggi. Namun, berdasarkan komposisi fraksi gasoline dalam penelitian Adrian [3] produk perengkahan sampah polystyrene foam suhu $360^{\circ} \mathrm{C}$ dengan katalis $\mathrm{H}$-Zeolit belum masuk ke dalam golongan gasoline karena masih mengandung $100 \%$ gologan aromatik. Kandungan senyawa aromatik yang tinggi dalam gasoline bersifat karsinogen, sebagai pembentuk deposit dan penyumbang emisi gas buang berbahaya [8].

\section{KESIMPULAN}

Hasil perengkahan sampah polystyrene foam pada suhu $360^{\circ} \mathrm{C}$ dengan katalis $\mathrm{H}$-Zeolit menghasilkan $85,52 \%$ fraksi gasoline dan 7,4\% fraksi kerosin dan diesel dengan komposisi fraksi gasoline 100\% golongan aromatik. Kandungan senyawa aromatik yang tinggi dalam gasoline bersifat karsinogen, sebagai pembentuk deposit dan penyumbang emisi gas buang berbahaya.

\section{REFERENSI}

[1] Miskudin Taufik, "Teluk Jakarta Jadi Sarang Sampah Plastik," 2019. https://itjen.kemdikbud.go.id/public/post/de tail/teluk-jakarta-jadi-sarang-sampahplastik (accessed Apr. 15, 2021).

[2] K. H. Lee, D. H. Shin, and Y. H. Seo, "Liquid-phase catalytic degradation of mixtures of waste high-density polyethylene and polystyrene over spent FCC catalyst. Effect of mixing proportions of reactants," Polym. Degrad. Stab., vol. 84, no. 1, pp. 123-127, Apr. 2004, doi: 10.1016/j.polymdegradstab.2003.09.019.

[3] Adrian, "Depolimerisasi Katalitik Sampah Plastik menjadi BBM menggunakan Limbah Katalis RFCC Pertamina UP-VI Balongan," 2013.

[4] Nurfathiyahalfi, "Bensin dan Bilangan Oktan.docx - Bensin dan Bilangan Oktan Bensin adalah salah satu jenis bahan bakar minyak yang dimaksudkan untuk kendaraan bermotor | Course Hero," 2019. https://www.coursehero.com/file/45124238 /Bensin-dan-Bilangan-Oktandocx/ (accessed Apr. 15, 2021).

[5] Ashadi, "Knocking Archives - Kimia itu Mudah," 2012. http://ashadisasongko.staff.ipb.ac.id/tag/kn ocking/ (accessed Apr. 15, 2021).

[6] T. H. Soerawidjaja, "Bahan-Bahan Bakar Hidrokarbon Utama: Bensin, Solar, dan Avtur," 2014.

[7] P. Ghosh, K. J. Hickey, and S. B. Jaffe, "Development of a detailed gasoline composition-based octane model," Ind. Eng. Chem. Res., vol. 45, no. 1, pp. 337345, 2006, doi: 10.1021/ie050811h.

[8] Anjar, "Efek Samping Sering Ganti Oktan BBM - Garasi.id," 2020. https://garasi.id/artikel/ganti-oktanbbm/59af7a6ce7ed0a12e93bfeec (accessed Apr. 15, 2021). 